\title{
A Designed Teaching Sequence as a Tool to Improve Students' Conceptual Understanding of the Conductivity in the Electrolytic Cell
}

\author{
Nur Jahan Ahmad ${ }^{1} \&$ Yahya Che Lah $^{2}$ \\ ${ }^{1}$ Institute of Teacher Education, Penang Campus, Malaysia \\ ${ }^{2}$ School of Distance Education, Universiti Sains Malaysia, Malaysia \\ Correspondence: Yahya Che Lah, School of Distance Education, Universiti Sains Malaysia, 11800 Penang, \\ Malaysia. Tel: 60-4-653-4569. E-mail: yahya@usm.my
}

Received: October 14, 2012 Accepted: November 21, 2012 Online Published: January 28, 2013

doi:10.5539/ass.v9n2p298 URL: http://dx.doi.org/10.5539/ass.v9n2p298

\begin{abstract}
This paper reports on a study to determine the efficacy of a teaching sequence following the Leeds model framework designed for a specific content of learning in electrochemistry. The design of the teaching draws upon theoretical insights into perspectives on learning and empirical studies to improve the teaching of this topic, specifically 'Electrolytic Cell'. A case study involving two classes, the Experimental and Baseline classes was carried out for 16-year-old Malaysian upper secondary school students. Also, eight classes of similar age in eight different schools who served as convenience samples (reference groups) were selected in order to compare the differences on their conceptual understanding in a wider sample. The evaluation of students' responses in one of the items in the post diagnostic test shows that there were significant differences in the experimental class students' performances in comparison to the baseline class students and the convenience samples. The experimental class students who followed the designed teaching sequence demonstrated better conceptual scientific understanding regarding the roles of ions and electrons in the conductivity of the electrolytic cell.
\end{abstract}

Keywords: pedagogy, design based research, teaching sequence, electrochemistry, electrolytic cell, social constructivism

\section{Introduction}

Research in chemistry education has shown that students often have difficulty in understanding chemistry concepts due to their abstract nature and many attempts have been made by researchers to assist students' learning by identifying the difficulties experienced by students and possible solutions to overcome this problem (Sanger \& Greenbowe, 1997a and 1997b; Niaz \& Chacon, 2003; Ozmen, 2004; Ozkaya et al., 2006). There are three levels of representation of chemical phenomena: macroscopic, sub-microscopic and symbolic (Treagust et al., 2003). The macroscopic level is an observable chemical event, e.g. observing the production of a new substance. In order to communicate regarding this macroscopic event, chemists commonly use symbolic representations such as chemical equations, reactions mechanisms, models and many other techniques (Treagust et al., 2003). Treagust et al. further add that the sub-microscopic level of representation is usually based on the particulate theory of matter, where the sub-microscopic entities are real, but are too small to be observed.

Some existing studies provide instruction to teachers on how to teach electrochemistry, either suggesting teaching instructions or teaching activity on how to improve teaching and learning this topic, for example, using cooperative learning instruction (Acar and Tarhan, 2007), conceptual change instruction (Ozkaya et al., 2006), or computer animated instruction (Sanger and Greenbowe, 2000). However, to my knowledge, no specific study has suggested a teaching intervention that provides detailed explanation on how to produce a designed teaching sequence for specific content on this topic, which can be replicated following the Malaysian context and curriculum.

\section{Statement of Problem}

Electrochemistry is the study of the inter-conversion of electrical and chemical energy which involves many examples of chemical observations, chemical reactions and symbols. There are two main electrochemical cells: the electrolytic and voltaic (galvanic) cells. These two cells have similar related features such as having two electrodes that are dipped into a solution known as electrolytes, and these two electrodes are connected to 
positive and negative terminals. Even though both electrochemical cells have similar terminologies, the outcomes for their chemical changes and reactions are different from one another. For example, in the electrolytic cell, the 'positive terminal' is known as the 'anode', whilst in the voltaic cell, the 'negative terminal' is similarly known as the 'anode'. Thus, the statement found in the Malaysian text book such as 'electrolytic cell is the reverse of the voltaic cell is an over generalised statement because not all features of both cells are the opposite of each other because the outcomes of the chemical changes and reactions and products at the electrodes are different.

In addition, some studies on this topic focus more on the voltaic cell (e.g. Boulabiar et al., 2004; Morikawa \& Williamson, 2001; Eilks et al., 2009), and others on comparing the chemical reactions in the electrolytic cell with the voltaic cell (Garnet \& Treagust, 1992b; Sanger \& Greenbowe, 1997b); but not so many studies on the electrolytic cell itself (see Ahtee et al., 2002). Even though the structure, chemical changes and reactions of the voltaic cell are more complicated than the electrolytic cell; an understanding of the structure of the electrolytic cell and its related features serves as a starting point for students to understand the whole process of electrochemistry. Thus, students need to be well versed in and appreciate the structure, chemical processes and reactions of the electrolytic cell because it is introduced in the first part of the electrochemistry syllabus before the voltaic cell. Also, students often fail to relate macroscopic observation with sub-microscopic entities, and cannot represent the chemical changes and reactions using symbolic entities (e.g. half cell equation). Thus, teaching should be designed to improve the students' understanding of these aspects in particular.

\section{Leeds Model Framework}

According to Millar et al. (2006), when we are interested in improving the teaching and learning of a specific content we need to consider the smaller 'units' so that it is easier to identify the intended learning outcomes. In addition, Leach and Scott (2008) state that, in designing a teaching sequence, features at both a large and fine grain size are important when designing teaching, as they address different levels and specificity in the teaching. For instance, at a large grain size, the conceptual framework of the social constructivist perspective on learning is presented where it is used to promote inquiry as a general pedagogic strategy, whilst at a fine grain size, this theory (social constructivism) is used to inform a specific pattern of teacher-student interaction (teacher-student talk) to address a specific learning goal. Similarly students' alternative conceptions on a topic from the literature and the pedagogical approach intended to be utilised in the teaching can be developed at both large and fine grain size, and both features are important in order to address the specific teaching aims in the designed teaching. The Leeds Model framework is informed at a large grain size by the 'social-constructivist' theoretical framing perspective. The design of the teaching is also informed at a fine grain size by the design tools that are used in the classroom teaching, namely the 'learning demands' and 'the communicative approach' (see Figure 1).

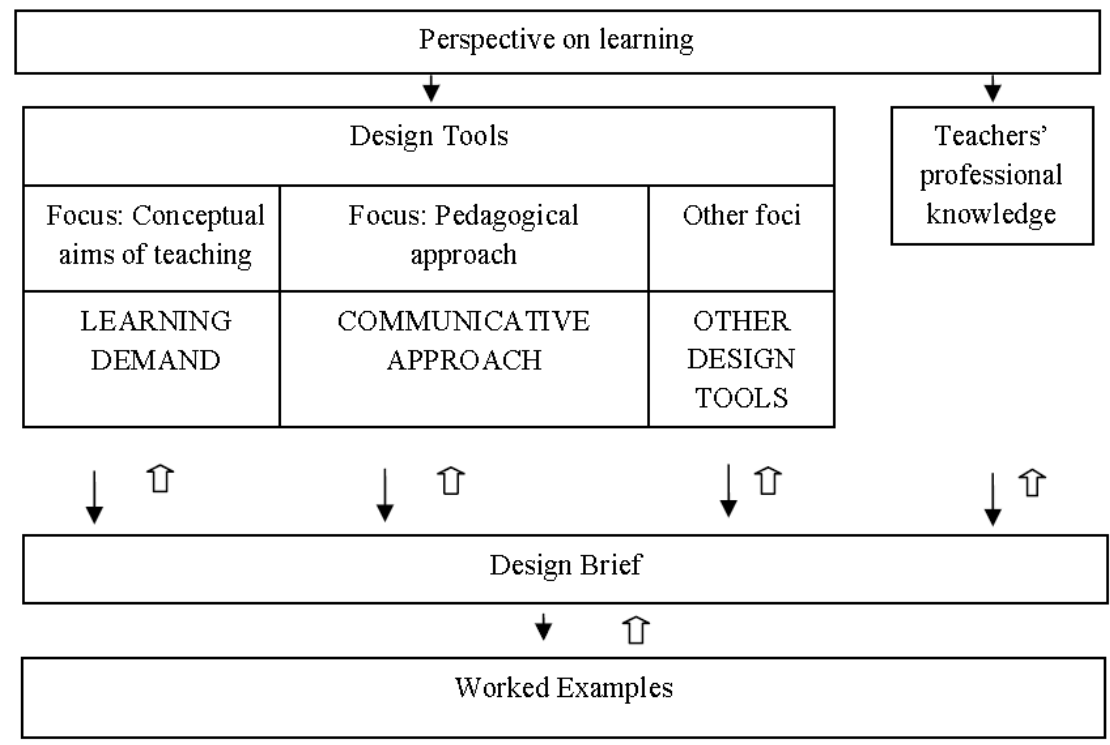

Figure 1. A research evidence-informed approach to designing science teaching (Ametller et. al, 2007)

Ametller et al. (2007, p.483) explain that the term 'design tools' refers to 'the concepts which draw upon theoretical perspectives on teaching and learning, and the products of empirical research on teaching and learning, to inform decisions about the design of teaching'. They refer the design tools as 'learning demands' 
and the 'communicative approach'. The notion of learning demands addresses the differences between students' everyday knowledge and the scientific knowledge; and this learning demand is linked to the classroom discourse, which is the communicative approach that is used on the social plane for student-teacher and student-student interaction in classroom. In addition, teachers' professional knowledge is accounted for the success of the design teaching. Thus, many aspects need to be considered in designing a teaching sequence.

\section{The Learning Demands Tool}

There are differences between everyday and scientific language in terms of both content and the nature of the knowledge used to represent the same phenomena, and these differences have created diverse kinds of intellectual demands. The extent of these differences in everyday language and the social language of science is referred to as 'learning demands' (Leach \& Scott, 2002, $2003 \&$ 2008). Based on this assumption, Leach and Scott (2002, 2003; also in Scott et al., 2006) adopt the notion of the 'learning demand' as a tool for students' thinking in a science classroom. Leach and Scott (2008) state that the concept of the learning demand itself is drawn upon the social constructivist view in which students' everyday social language is identified and compared with the social language of school science. Furthermore, students' everyday reasoning provides the starting point for thinking about the design of the Teaching Sequence. Leach and Scott (2003) claim that the bigger the learning demand, the greater the challenge for teachers to assist students to make sense of the scientific theories or concepts. The learning demand is used to challenge students regarding their existing beliefs about a particular scientific matter. Thus, designers must be able to predict the learning demands associated with the differences between students' ideas and the scientific view.

\section{Implications for the Design of Teaching: Addressing the Learning Demand}

Leach and Scott $(2002$, p.127) have outlined the following scheme as a guide to planning teaching interventions:

1) Identify the school science knowledge to be taught.

2) Consider how this area of science is conceptualized in the everyday reasoning of students.

3 ) Identify the learning demand by appraising the nature of any differences (conceptual, epistemological, and ontological) between (1) and (2).

4) Design the teaching intervention to address each aspect of this learning demand by:

a) identifying the teaching goals for each phase of the intervention;

b) planning a sequence of activities to address the specific teaching goals;

c) specifying how these teaching activities might be linked to appropriate forms of classroom communication.

The above points reveal the strength of this Model framework whereby the emphasis is placed on students' difficulties by performing an analysis of students' ideas in the literature, school textbooks and chemistry syllabus and then formulating them as learning demands to be addressed in teaching design at a fine grain size. Furthermore, with regard to classroom teaching (in the Malaysian context), the teachers basically teach according to the descriptions in the school chemistry syllabus and are not aware of the difficulties that students face before and after teaching. Thus, the teacher can support this aspect of design in order to teach students to gain a better conceptual understanding of a difficult subject matter.

\section{Subject and Sample Size}

A case study encompassing two classes was conducted in one school in Penang: an experimental class (37 students) who followed the designed teaching sequence and a baseline class (27 students) who served as a comparison group and followed a similar curriculum and normal classroom teaching. The school was not chosen from a random sample because it was selected based on having more than one class science and the students have similar academic ability. This is to ensure that the findings from this study were solely based on the differences in the teaching materials used.

Also, eight classes in eight different schools (189 students) who served as convenience samples and reference groups were selected in order to compare the differences on their conceptual understanding of aspects of electrochemistry in a wider sample. Similar post diagnostic test papers were given to the students after they had been taught electrochemistry. The results from the students' responses were later compared with those from the experimental and baseline classes.

\section{Data Collection Methods}

The data collected in this study was mainly focused on the responses in the post diagnostic test. The recorded teaching for each lesson in the experimental class was the second main data in this study and was used in order 
to analyse the sequencing of the content in the actual teaching. This data was later compared with the contents of the designed teaching. Finally, the interview data from the students and the teacher were gathered and treated as additional research data in order to support the findings from the post diagnostic test and the teaching analysis regarding the students' and teacher's perceptions of the teaching.

In this paper, only the data in one of the items in the post diagnostic test are presented.

\section{Data Analysis}

The analysis in this study starts by using the ideographic approach, followed by the nomothetic approach. After the ideographic analysis of the students' responses, the following coding schemes are applied as a means to analyse students' responses using the nomothetic approach (Driver \& Erickson, 1983).

For example, one of the students' responses:

'There is a flow of electricity in the wire' (Student A)

This response shows that Student A understood that there is a flow of electricity in the wire that makes it possible to light up the bulb, but the response does not contain the taught key features; that is, 'this is because electrons move in the wire from the anode to the cathode'. Thus, this response is analysed ideographically. However, as this response is coded as partially correct, this is a nomothetic analysis. There are four types of categories (set) are developed, which are 'Scientifically correct (SC), Partially correct (PC), Other (O)' and 'Not attempted (NA)'. The results from the experimental and baseline class are compared using a Chi-square test of independence while the results in other eight schools (convenience samples) are presented in the form of percentages as the values are not compared in terms of significant difference but just to determine the numbers of 'scientifically correct' and other categories.

\section{Results and Discussions}

Table 1 shows the results for the experimental and baseline classes on one of the learning area under investigation which is aimed to investigate students' conceptual understanding about the nature and properties of electrolytes and electrons that influence the conductivity in the electrolytic cell. The five items in the question 1 relate to electrolyte having negative (anion) and positive (cation) ions, and only being able to conduct electricity when they are in an aqueous (1a) or molten state (1c) whilst not being able to do so when in a solid state (1b). Furthermore, the students' understanding of the properties of non-electrolytes (e.g. properties of covalent compound) is also investigated (1d). Finally, the students were required to define an electrolyte in the last question (1e).

Table 1 below shows that there were significant differences in the number of correct responses between the experimental and baseline groups relating to the nature and properties of electrolytes for items $1 \mathrm{a}, 1 \mathrm{~b}, 1 \mathrm{c}$ and $1 \mathrm{e}$, meaning that more students in the experimental class were able to answer correctly compared to the baseline class. Even though there was no significant difference for item 1d, it still shows that about $18 \%$ more students in the experimental class performed better than the baseline class.

Table 1. Chi-square results for the 'scientifically correct' answers in question 1

\begin{tabular}{|c|c|c|c|c|c|c|c|c|c|}
\hline \multirow{2}{*}{ Question } & \multicolumn{2}{|c|}{ Exp } & \multicolumn{2}{|c|}{ Bl } & \multirow{2}{*}{$\begin{array}{c}\text { Chi-square } \\
\left(\chi^{2}\right)\end{array}$} & \multirow{2}{*}{$\begin{array}{c}\text { Probability } \\
\text { (p) }\end{array}$} & \multirow{2}{*}{$\begin{array}{c}\text { Fisher } \\
\text { exact test }\end{array}$} & \multirow{2}{*}{$\begin{array}{l}\text { Chi-square } \\
\text { critical }\left(\chi^{2}\right)\end{array}$} & \multirow{2}{*}{$\begin{array}{c}\alpha \\
\text { (critical) }\end{array}$} \\
\hline & SC & $\%$ & SC & $\%$ & & & & & \\
\hline $1 \mathrm{a}$ & 26 & 70.3 & 8 & 29.6 & 10.35 & 0.001 & 0.002 & 6.64 & 0.01 \\
\hline $1 b$ & 30 & 81.1 & 6 & 22.2 & 21.97 & 0.000 & 0.000 & 10.83 & 0.001 \\
\hline $1 \mathrm{c}$ & 29 & 78.4 & 5 & 18.5 & 22.46 & 0.000 & 0.000 & 10.83 & 0.001 \\
\hline 1d & 19 & 51.4 & 9 & 33.3 & 2.06 & 0.151 & 0.204 & 3.84 & 0.05 \\
\hline $1 \mathrm{e}$ & 15 & 40.5 & 4 & 14.8 & 4.95 & 0.026 & 0.030 & 3.84 & 0.05 \\
\hline
\end{tabular}

The results for the eight different schools after they had been taught the topic are shown in Table 2 below. For item $1 \mathrm{a}, 1 \mathrm{~b} \& 1 \mathrm{c}$ presented in Table 2, it can be seen that none of the classes were able to achieve more than $50 \%$ 'scientifically correct' answers. 
Table 2. Results of the 'scientifically correct' (SC) answers for item 1 in eight schools

\begin{tabular}{llllll}
\hline Class/Items (\%) & $\mathbf{1 a}$ & $\mathbf{1 b}$ & $\mathbf{1 c}$ & $\mathbf{1 d}$ & $\mathbf{1 e}$ \\
\hline $\mathbf{A}$ & $35.1 \%$ & $35.1 \%$ & $29.7 \%$ & $56.8 \%$ & $18.9 \%$ \\
$\mathbf{B}$ & $27.6 \%$ & $37.9 \%$ & $24.1 \%$ & $17.2 \%$ & $3.4 \%$ \\
$\mathbf{C}$ & $18.5 \%$ & $14.8 \%$ & $14.8 \%$ & $22.2 \%$ & $7.4 \%$ \\
$\mathbf{D}$ & $30.4 \%$ & $39.1 \%$ & $39.1 \%$ & $43.5 \%$ & $8.7 \%$ \\
$\mathbf{E}$ & $18.2 \%$ & $18.2 \%$ & $18.2 \%$ & $40.9 \%$ & $27.3 \%$ \\
$\mathbf{F}$ & $22.7 \%$ & $27.3 \%$ & $22.7 \%$ & $18.2 \%$ & $0.0 \%$ \\
$\mathbf{G}$ & $6.7 \%$ & $6.7 \%$ & $46.7 \%$ & $13.3 \%$ & $80.0 \%$ \\
$\mathbf{H}$ & $21.4 \%$ & $7.1 \%$ & $28.6 \%$ & $35.7 \%$ & $28.6 \%$ \\
\hline
\end{tabular}

The results illustrate that the students' performances were very weak and clearly show that they were having difficulties explaining the properties of electrolytes that makes them able to light up the bulb when in an aqueous and molten state, and also the reason the bulb does not light up when the electrolytes are in solid state. For item 1e in Table 2, it can be seen that only one class (Class G) was able to achieve $80 \%$ 'scientifically correct' answers which asks students the definition of 'electrolyte'.

Following the above discussions, students' difficulties were divided into two main areas:

1) Not able to generate detailed explanations of the chemical event.

2) Not able to relate the macroscopic, sub-microscopic and symbolic entities, or to relate any of the two entities.

The findings show that students who were from the baseline class and followed the normal classroom teaching were mainly weak in answering the 'scientifically correct' (SC) answers. They showed lack of understanding regarding the roles of ions and electrons in the solution and external wire respectively. Furthermore, most of the 'scientifically correct' responses were very short and simple but they were accepted as 'scientifically correct' because students may have difficulty generating detailed explanations in English as it is not their first language; thus, it is not expected that the most of the responses provided by the students would contain detailed descriptions of the chemical event. However, there were responses that showed some students were able to provide good scientific knowledge, even though the numbers were small. Below are two responses from students in Class A for item 1a.

'There are freely moving ions' [Student X]

'Aqueous $\mathrm{X}$ contains free-moving ions' [Student $\mathrm{Y}$ ]

In comparison to the experimental class, the explanation was more specific and details of the chemical process were illustrated clearly as shown below:

'I think the aqueous allows the bulb to light up because the ions that is anion and cation move to anode and cathode respectively. This will cause freely moving electrons in the circuit and will produce electric current' [Student R]

'In aqueous $\mathrm{X}$, there is freely moving ions of substance $\mathrm{X}$. The freely moving ions allow the electricity to flow. Therefore, the circuit is complete. So, the bulb will lights up' [Student S]

Furthermore, in the baseline class and the convenience samples, there were responses which showed some spelling and grammatical errors, but as long as the responses were understandable, they were coded according to the coding schemes mentioned earlier. Also from the responses, some students did not demonstrate confidence writing their answers, probably because it is in English. In addition, there were many students who did not attempt the questions, which might be because they found the questions difficult; and it was also possible that they may not take the questions seriously because the test was not an examination paper.

Also, most of the responses in the baseline class and the convenience samples did not demonstrate many misconceptions because most of the responses indicate that students experienced difficulties in generating explanations from the taught content; for example, explaining the concepts, the terms, and the chemical changes and reactions that occur in the electrolytic cell. It is found that many students were unable to generate an explanation about the chemical event based on factual recall. Thus, the main difficulties that are faced by the students are not about developing misconceptions after they have been taught the topic; but rather the difficulties lie more with generating detailed explanations regarding the chemical event. 
Following the above results on students' ideas about ions and electrons in the electrolytic cell, students were found to have difficulties relating the three entities, which are: macroscopic, sub-microscopic and symbolic. In some cases (not always), there are only two entities involved; for example, macroscopic observation is explained by using the sub-microscopic entities, and sometimes it is not necessary to present the symbolic entities, or the sub-microscopic entities with symbolic entities.

\section{Conclusions}

The data presented from the chi-square analysis were able to show the differences between the experimental and baseline students' performance in item 1 . There were differences in their conceptual understanding especially when the students provided descriptive explanations that require further elaboration. The students in the experimental class provided better structured and more precise answers, showing that they had better scientific understanding and were more confident in writing their responses than the baseline class, whose answers are shorter and lack some taught key features of the scientific explanation. The analyses echo those students in the baseline class who were unable to generate detailed factual explanations in their responses, similar to those of eight classes (convenience samples). Consequently, this study has provided evidence that students in the experimental class were able to generate more detailed explanations in their responses.

Furthermore, the students in the experimental class appeared able to relate their macroscopic observation to sub-microscopic entities (or two entities) from their written responses compared to the baseline class (this is also observed in the reference group). For example, almost more than $50 \%$ (even higher) of students in the experimental class were able to relate the presence of the freely moving ions in the electrolyte (sub-microscopic) with the bulb lighting up (macroscopic). In another instance, the students were able to relate the bulb lighting up with the movements of electrons.

From the findings obtained from the analysis of the results, the evidence shows that students in the experimental class developed a better conceptual understanding following teaching, in comparison to the baseline class and the convenience samples. Thus, there must be some aspects of the designed teaching sequence that contribute to these differences in the achievement of these classes.

The eight classes that were chosen as convenience samples (reference groups) reflect typical schools in Malaysia who followed normal classroom teaching with the same content as stated in the chemistry syllabus. The findings in this study have provided some empirical evidence that many students developed conceptual difficulties in this learning area and the results do not support any assumption that normal classroom teaching has provided essential support for students to generate detailed, factual explanations about the chemical event (phenomena). This shows that this is a serious matter to be tackled in the classroom teaching and learning regarding a specific, difficult area in chemistry. Also, the findings suggest that the typical classroom teaching and learning may be unsuitable for improving students' conceptual understanding in relating the three levels of representation in learning chemistry when connecting the macroscopic, sub-microscopic and symbolic entities. Drawing from this, the effectiveness of the designed teaching sequence can be determined according to whether or not students in the experimental class had developed a better conceptual understanding after teaching in comparison to the baseline class and the reference group in this study. In conclusion, as mentioned at the end of the discussions regarding the roles of ions and electrons in the conductivity of the electrolytic cell, some aspects of the designed teaching sequence may have achieved the particular teaching and learning aims, but other aspects may not be as successful. However, the designed teaching sequence has a promising potential to be used as a tool in the Malaysian classroom in order to improve students' conceptual scientific understanding of a particular aspect in electrochemistry.

\section{References}

Acar, B., \& Tarhan, L. (2007). Effect of cooperative learning strategies on students' understanding of concepts in electrochemistry. International Journal of Science and Mathematics Education, 5, 349-373. http://dx.doi.org/10.1007/s10763-006-9046-7

Ahtee, M., Asunta, T., \& Palm, H. (2002). Student teachers' problem in teaching 'electrolysis' with a key demonstration. Chemistry Education: Research and Practice in Europe, 3(3), 317-327. http://dx.doi.org/10.1039/b0rp90031a

Ametller, J., Leach, J., \& Scott, P. (2007). Using perspective on subject learning to inform the design of subject teaching: an example from science education. The Curriculum Journal, 18(2), 479-492. http://dx.doi.org/10.1080/09585170701687928 
Boulabiar, A., Bouraoui, K., Chastrette, M., \& Abderrabba, M. (2004). A historical analysis of the Daniell cell and electrochemistry teaching in French and Tunisian textbooks. Journal of Chemical Education, 81(5), 754-757. http://dx.doi.org/10.1021/ed081p754

Driver, R., \& Erickson, G. (1983). Theories-in-action: Some theoretical and empirical issues in the study of students' conceptual frameworks in science. Studies in Science Education, 10, 37-60. http://dx.doi.org/10.1080/03057268308559904

Eilks, I., Witteck, T., \& Pietzner, V. (2009). A critical discussion of the efficacy of using visual learning aids from the internet to promote understanding, illustrated with examples explaining the Daniell voltaic cell. Eurasia Journal of Mathmatics. Science \& Technology Education, 5(2), 145-152.

Garnett, P. J., \& Treagust, D. F. (1992). Conceptual difficulties experienced by senior high school students of electrochemistry: Electrochemical (galvanic) and electrolytic cells. Journal of Research in Science Teaching, 29(2), 1079-1099. http://dx.doi.org/10.1002/tea.3660291006

Leach, J., \& Scott, P. (2002). Designing and evaluating science teaching sequences: an approach drawing upon the concept of learning demand and a social constructivist perspective on learning. Studies in Science Education, 38, 115-142. http://dx.doi.org/10.1080/03057260208560189

Leach, J., \& Scott, P. (2003). Individual and sociocultural perspectives on learning in science education. Science Education, 12, 91-113. http://dx.doi.org/10.1023/A:1022665519862

Leach, J., \& Scott, P. (2008). Teaching for conceptual understanding: an approach drawing on individual and sociocultural perspectives. In S. Vosniadou (Ed.), International handbook of research on conceptual change (pp. 647-675). London: Routledge.

Millar, R., Leach, J., Osborne, J., \& Ratcliffe. (2006). Improving practice in subject teaching: the contribution of research. In R. Millar, J. Leach, \& M. Ratcliffe (Eds.). Improving Subject Teaching: Lessons from research in science education (pp. 60-78). London: Taylor and Francis.

Morikawa, T., \& Williamson, B. E. (2001). Model for teaching about electrical neutrality in electrolyte solutions. Journal of Chemical Education, 78(7), 934-936. http://dx.doi.org/10.1021/ed078p934

Niaz, M., \& Chacon, E. (2003). A conceptual change teaching strategy to facilitate high school students' understanding of electrochemistry. Journal of Science Education and Technology, 12(2), 129-134. http://dx.doi.org/10.1023/A:1023983626388

Özkaya, A. R., Uce, M., Saricayir, H., \& Sahin, M. (2006). Effectiveness of a conceptual change-oriented teaching strategy to improve students' understanding of galvanic cells. Journal of Chemical Education, 83(11), 1719-1723. http://dx.doi.org/10.1021/ed083p1719

Özmen, H. (2004). Some students misconceptions in chemistry: A literature review of chemical bonding. Journal $\begin{array}{lllll}\text { of Science Education } & \text { 137 }\end{array}$ http://dx.doi.org/10.1023/B:JOST.0000031255.92943.6d

Sanger, M. J., \& Greenbowe, T. J. (1997a). Students' misconceptions in electrochemistry: current flow in electrolyte solutions and the salt bridge. Journal of Chemical Education, 74(7), 819-823. http://dx.doi.org/10.1021/ed074p819

Sanger, M. J., \& Greenbowe, T. J. (1997b). Common student misconceptions in electrochemistry: Galvanic, electrolytic and concentration cells. Journal of Research in Science Teaching, 34(4), 377-398. http://dx.doi.org/10.1002/(SICI)1098-2736(199704)34:4<377::AID-TEA7>3.0.CO;2-O

Sanger, M. J., \& Greenbowe, T. J. (2000). Addressing student misconceptions concerning electron flow in aqueous solutions with instruction including computer animations and conceptual change strategies. International Journal of Science Education, 22(5), 521-537. http://dx.doi.org/10.1080/095006900289769

Scott, P., Leach, J., Hind, A., \& Lewis, J. (2006). Designing research evidence informed teaching interventions. In R. Millar, J. Leach, \& M. Ratcliffe (Eds.), Improving Subject Teaching: Lessons from research in science education (pp. 60-78). London: Taylor and Francis.

Treagust, D. F., Chittleborough, G., \& Mamiala, T. L. (2003). The role of submicroscopic and symbolic representations in chemical explanations. International Journal of Science Education, 25(11), 1353-1368. http://dx.doi.org/10.1080/0950069032000070306 